\title{
On the low-cycle fatigue capacity of unanchored steel liquid storage tank shell-to-base connections
}

\author{
Gary S. Prinz • Alain Nussbaumer
}

Received: 8 February 2012 / Accepted: 11 September 2012 / Published online: 22 September 2012

C) Springer Science+Business Media Dordrecht 2012

\begin{abstract}
Under strong earthquake motions, the liquid stored within large unanchored steel tanks can cause rocking and uplift of the tank base from the supporting foundation. Repeated rocking can lead to low-cycle fatigue fractures in the tank base-plate, and ultimately spillage of tank contents. Due to limited research on tank connection capacity, current European and New Zealand tank standards (EuroCode8 part 4 and NZSEE) impose unjustified rotation limits on tank shell-to-base connections (current limit being $0.2 \mathrm{rad}$ ). These rotation limits often govern the design of new tanks, and many existing tanks require retrofit to meet compliance. This paper experimentally investigates the fatigue capacity of tank shell-to-base connections, with a focus on the effects from material ductility and applied strain range (rotation range). Twenty-seven tank connections representing two steel material grades are fatigue tested under constant range rotation cycles to generate fatigue-life curves. Tensile loads applied to the base-plate simulate membrane action present in tanks during uplift. Results indicate that the strain capacity of the base-plate base material strongly influences connection fatigue capacity as fatigue fractures originate in the base material away from the weld toe and weld heat affected zone. Increasing base-plate ductility drastically increases connection fatigue life. All connection specimens sustained multiple uplift cycles at rotations greater than the existing EuroCode8 and NZSEE limits.
\end{abstract}

Keywords Experimental testing · Unanchored steel tanks · Low cycle fatigue · Earthquake design

\section{Introduction}

The base of large unanchored liquid storage tanks can uplift during extreme seismic events. During uplift, deflections of the tank base-plate can create large inelastic rotation demands

G. S. Prinz $(\bowtie) \cdot$ A. Nussbaumer

Steel Structures Laboratory (ICOM), École Polytechnique Fédérale de Lausanne (EPFL),

Lausanne, Switzerland

e-mail: gary.prinz@epfl.ch 
Fig. 1 Uplift of tank base and shell-to-base connection rotation

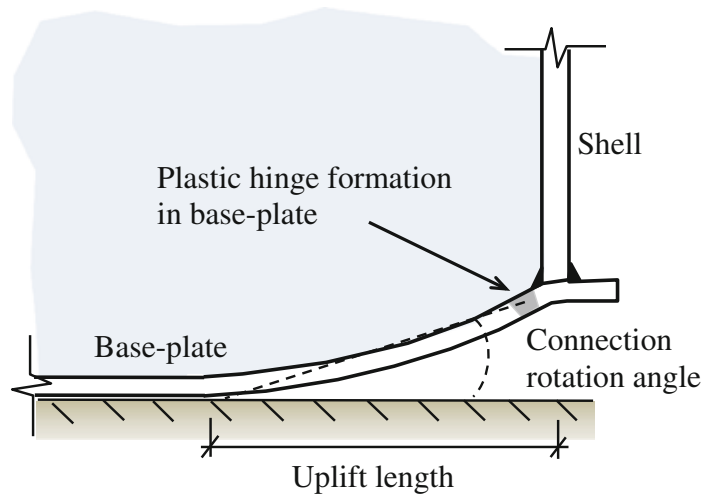

at the shell-to-base connection (see Fig. 1) (Fujikazu et al. 1988; Peek 1988; Peek and Jennings 1988), potentially leading to low-cycle fatigue fractures after repeated cycles of uplift. Because base-plate fractures have significant economic and environmental consequences, understanding the rotation capacity of tank shell-to-base connections is vital in the design of new tanks, and in the analysis of existing tanks.

Multiple studies have investigated tank demands during earthquake loading, including fluid-tank interactions, soil-tank interactions, and base uplift behavior (Jacobsen 1949; Housner 1963; Leon and Kausel 1986; Malhotra and Veletsos 1994a,b; Malhotra 1995); however, until recently, no study had investigated the rotation capacity of tank connections. Due to limited experimental research on the rotation capacity of tank connections, design guidelines have been forced to impose unjustified capacity limits. Current tank design guidelines, Eurocode 8 (1998) part 4 (hereafter referred to as EC8-4) and NZSEE (2009), limit connection rotations to less than 0.2 rad for an unspecified number of uplift cycles based on an assumed allowable base-plate strain of $5 \%$. Statements in the code commentaries suggest that this $5 \%$ strain limit is to provide a somewhat conservative capacity given the limited research on tank connections. There is no research given to back this $5 \%$ strain limit assumption.

Experience from past earthquakes would suggest that tank shell buckling, or pipeline rupture is of greater concern than shell-to-base connection fracture; however, shell-to-base rotation limits continue to govern the design of new tanks, and many existing tanks require retrofit to meet compliance. Following the 1979 Imperial Valley and 1983 Coalinga California earthquakes, evaluation of existing tank farms found evidence of tank rocking and base-plate uplift, with no evidence of base-plate fractures (Haroun 1983; Manos and Clough 1985). The predominate damages observed following both events were: elephant foot buckling of the tank shell, tank roof damage due to liquid sloshing, and rupture of connecting pipes. An investigation of six unanchored steel tanks from within Switzerland (Koller 2003) found that four existing shell-to-base connections did not satisfy the current EC8-4 0.2rad rotation limit, which combined with the limited evidence of tank base-plate fractures, prompted an experimental investigation by Cortes et al. (2011) to determine realistic rotation capacities of tank shell-to-base connections.

In Cortes et al. (2011), 24 shell-to-base connections having multiple thicknesses and levels of radial membrane load were tested to failure under various ranges of cyclic rotation. Results indicated reasonable connection capacity up to $0.4 \mathrm{rad}$, the largest rotation tested; however, a limited number of experiments were carried out at each rotation value, reducing statistical significance of the results. Additionally, testing of a few corroded tank specimens taken from existing tanks suggested that connections fabricated with S235 steel may be more 


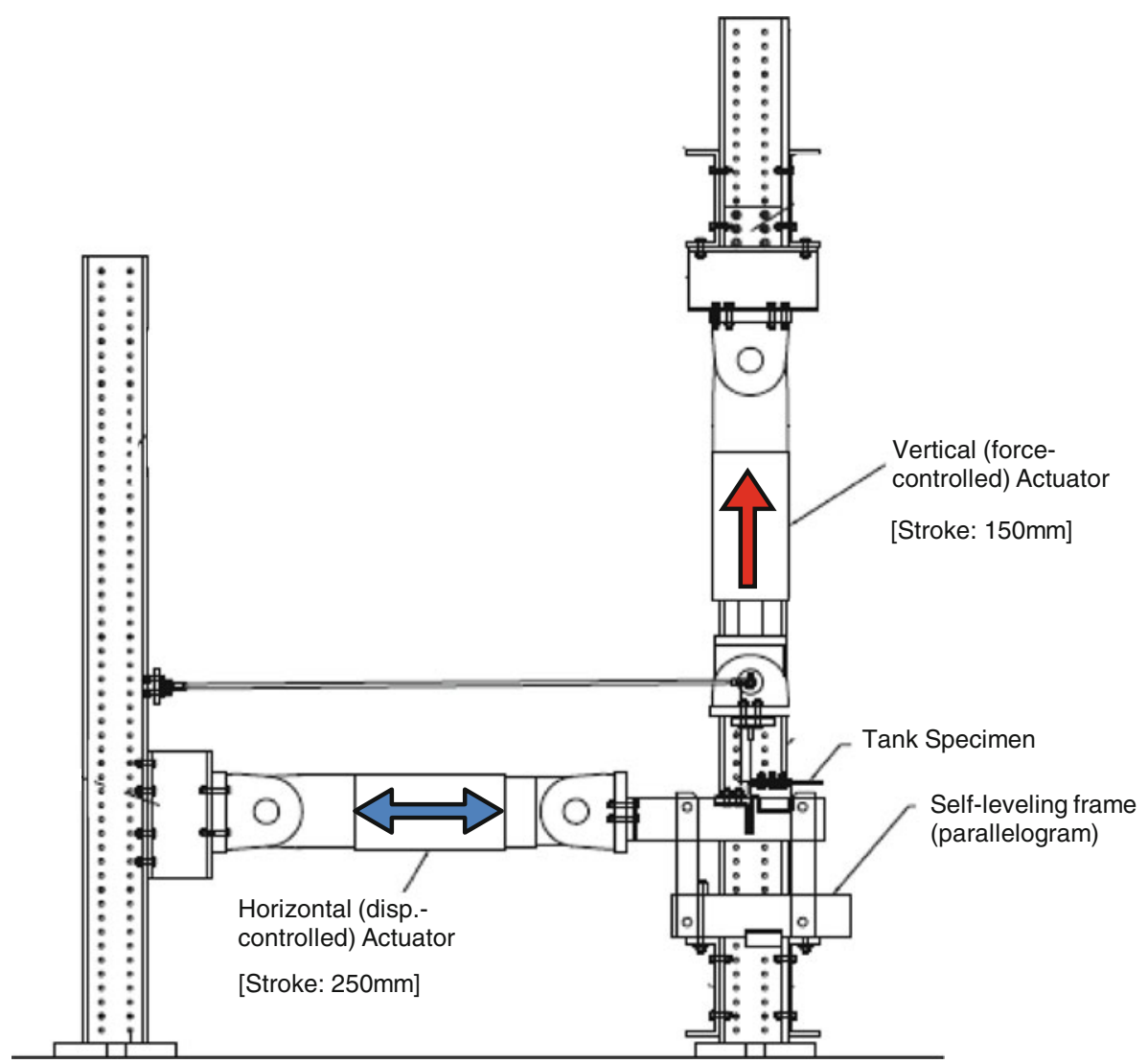

Fig. 2 Experimental setup

ductile and less susceptible to low-cycle fatigue than specimens fabricated with S355 steel, however this was not confirmed with further testing.

This paper aims to expand upon the research by Cortes et al. (2011) by examining the effects of base-plate ductility on connection rotation capacity, increasing the sample size of tested connections for statistical significance, and determining connection capacities at higher rotation ranges. The paper begins by describing the experimental methods used to determine rotation capacity, including the test setup, instrumentation, cyclic loading proto$\mathrm{col}$, and specimen connection detail. Material characterization tests are performed to identify variations in material parameters. Lastly, fatigue results from the connection test specimens are discussed, and conclusions regarding the capacity of tank connections are presented.

\section{Experimental setup and test specimen}

The test setup shown in Fig. 2 is designed to simulate the force and deformation demands present in tank shell-to-base connections during earthquake induced uplift. Similar to the test setup used by Cortes et al., two hydraulic actuators load the test specimens (one force controlled and the other displacement controlled), while a self-leveling frame ensures proper 

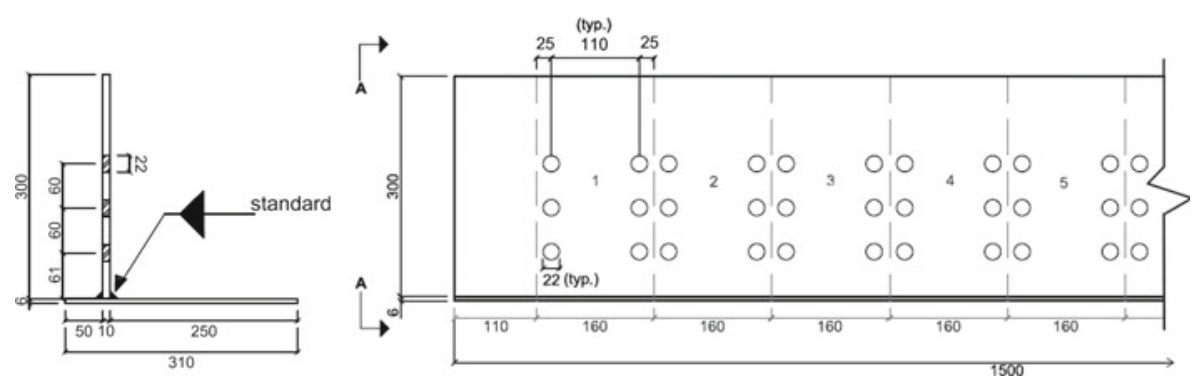

Fig. 3 Specimen dimensions and fabrication method

specimen orientation. The vertical actuator in the assembly applies a constant axial load to the specimen base-plate to simulate radial membrane effects that occur in fluid-filled tanks during uplift. The horizontal actuator applies the uplift displacements. For consistency between connections having different material strengths, the membrane load is applied as a percentage of the nominal base-plate yield strength. In Fig. 2, the connection specimen is rotated $90^{\circ}$ such that the tank base is parallel with the vertical actuator.

All tank shell-to-base connection specimens were created according to industry standard practice for fabrication of steel storage tanks. Portions of a steel tank were constructed using steel plates (representing the tank shell and base) attached using a continuous fillet weld of S355 material along the plate length. The number of weld passes was determined by the tank manufacturer according to typical convention for welding of real tank connections (note two weld passes for the plate thicknesses used in this study). After attachment of the base and shell plates, individual tank specimens were cut from the welded assembly. In total, twenty-seven connection specimens were fabricated, representing two steel material grades. In actual constructed tanks, transverse welds can be present at the junction of two adjacent base-plates; however these welds were not considered in the test specimen fabrication.

Two different material grades were chosen to investigate the effect of plate ductility on connection fatigue life. Steel grades S355 J2+N and S235 JR+AR were chosen based on recommendations of commonly used materials from tank fabricators, and based on material testing of existing tanks within Switzerland (Cortes et al. 2011). Within the S355 J2+N material grade, two different material fabrication batches were tested, a Phase-1 batch (fabricated in early 2010 for the testing performed by Cortes et al.) and a Phase- 2 batch (fabricated in early 2011 for the current study). Due to the S355 weld material, an overmatching and matching material strength situation was created at the connection weld for the S235 and S355 specimens, respectively. A generic specimen detail is shown in Fig. 3 and Table 1 provides the specimen test matrix

\subsection{Instrumentation}

Several external measuring devices were added to the test setup to ensure accurate loading, and to provide information for assessing connection performance. An external linear variable differential transducer (LVDT), multiple strain gauges, and an inclinometer were all attached to the tank specimen during loading to ensure the accuracy of the applied loads and displacements. The LVDT was attached near the specimen base, and was used to confirm horizontal displacements applied by the displacement controlled actuator. The inclinometer was attached to the edge of the base-plate, near the vertical actuator connection, to confirm applied 
Table 1 Test specimen summary

\begin{tabular}{lllllll}
\hline Group & $\begin{array}{l}\text { No. of } \\
\text { specimens }\end{array}$ & $\begin{array}{l}\text { Base } \\
\text { thickness } \\
(\mathrm{mm})\end{array}$ & $\begin{array}{l}\text { Wall } \\
\text { thickness } \\
(\mathrm{mm})\end{array}$ & $\begin{array}{l}\text { Rotation } \\
(\mathrm{rad})\end{array}$ & Steel grade & $\begin{array}{l}\text { Nominal axial load } \\
\left(\% \sigma_{y}(\mathrm{kN})\right)\end{array}$ \\
\hline A & 4 & 10 & 15 & 0.5 & $\mathrm{~S} 355 \mathrm{~J} 2+\mathrm{N}$ & $10(57)$ \\
B & 5 & 6 & 10 & 0.5 & $\mathrm{~S} 355 \mathrm{~J} 2+\mathrm{N}$ & $10(34)$ \\
C & 3 & 6 & 10 & 0.4 & $\mathrm{~S} 355 \mathrm{~J} 2+\mathrm{N}$ & $10(34)$ \\
D & 3 & 6 & 10 & 0.3 & $\mathrm{~S} 355 \mathrm{~J} 2+\mathrm{N}$ & $10(34)$ \\
E & 4 & 6 & 10 & 0.3 & $\mathrm{~S} 235 \mathrm{JR}+\mathrm{AR}$ & $10(23)$ \\
F & 5 & 6 & 10 & 0.4 & $\mathrm{~S} 235 \mathrm{JR}+\mathrm{AR}$ & $10(23)$ \\
G & 3 & 5 & 10 & 0.5 & $\mathrm{~S} 355 \mathrm{~J} 2+\mathrm{N}$ & $10(28)$ \\
\hline
\end{tabular}

a Tensile membrane load based on nominal material yield strength

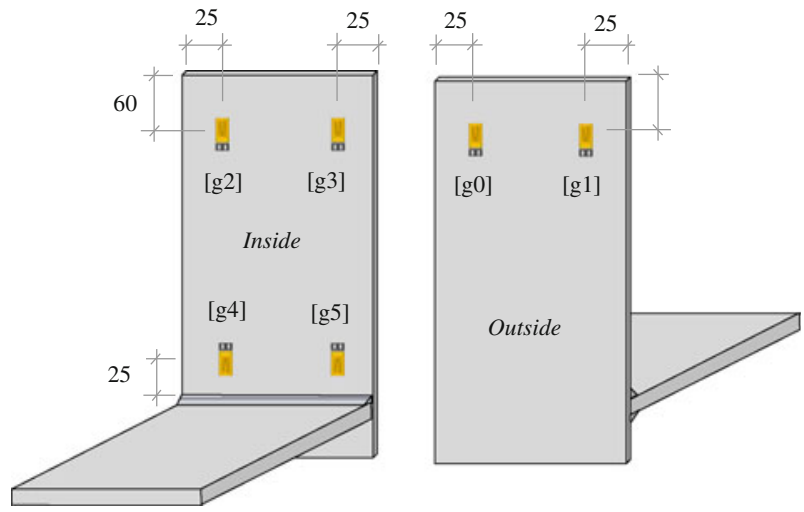

Fig. 4 Strain gauge locations

rotations. The multiple strain gauges provided validation of applied stress and allowed for determination of damage evolution (accumulation of plastic strains) at the specimen surface (see Fig. 4 for strain gauge placement).

\subsection{Cyclic loading protocol}

To determine connection fatigue-life, tank specimens were subjected to constant range rotation cycles until failure. For the purpose of this study, specimen failure is defined as complete rupture of the tank base-plate from the tank shell. The chosen rotation ranges for this study are 0.3, 0.4, and 0.5 rad. Specimens in Groups A, B and G (see Table 1) are subjected to repeated cycles at $0.5 \mathrm{rad}$, specimens in Groups $\mathrm{C}$ and $\mathrm{F}$ are subjected to $0.4 \mathrm{rad}$, and specimens in Groups $\mathrm{D}$ and $\mathrm{E}$ are subjected to $0.3 \mathrm{rad}$. One advantage of a constant range loading history is that there is no need to convert intermediate smaller cycles into an equivalent number of larger cycles using an assumed damage law or other such method. This simplifies the fatigue analysis and directly determines rotation capacity in terms of the number of cycles to failure, $N_{f}$.

It is important to note that the deformation protocol for the tank base-plate assumes a rigid tank foundation (i.e. penetrations beyond the initial datum are not considered). 
Table 2 Tensile coupon material data

\begin{tabular}{lllll}
\hline $\begin{array}{l}\text { Material } \\
\text { specimen ID }\end{array}$ & Material grade & $\begin{array}{l}\text { Measured } \\
\text { yield }\end{array}$ & $\begin{array}{l}\text { Toughness } \\
\text { modulus }(\mathrm{MPa})\end{array}$ & $\begin{array}{l}\text { Fracture } \\
\text { strain, } \varepsilon_{f}\end{array}$ \\
\hline $\mathrm{CI}$ & $\mathrm{S} 355 \mathrm{~J} 2+\mathrm{N}$ & 382 & 160.3 & 0.348 \\
$\mathrm{CII}$ & $\mathrm{S} 355 \mathrm{~J} 2+\mathrm{N}$ & 389 & 167.7 & 0.361 \\
$\mathrm{DI}$ & S235 JR+AR & 261 & 149.5 & 0.389 \\
DII & S235 JR+AR & 276 & 131.0 & 0.373 \\
EI $^{\mathrm{b}}$ & S355 J2+N & 389 & 131.6 & 0.252 \\
EII $^{\mathrm{b}}$ & S355 J2+N & 411 & 84.3 & 0.163 \\
EIII $^{\mathrm{b}}$ & S355 J2+N & 411 & 78.0 & 0.152 \\
\hline
\end{tabular}

a Determined from $0.2 \%$ strain offset

${ }^{b}$ Material taken from Phase-1 test specimens

Fig. 5 Stress versus strain behavior for S355 Phase-1, S355 Phase-2, and S235 material specimens $(6 \mathrm{~mm})$

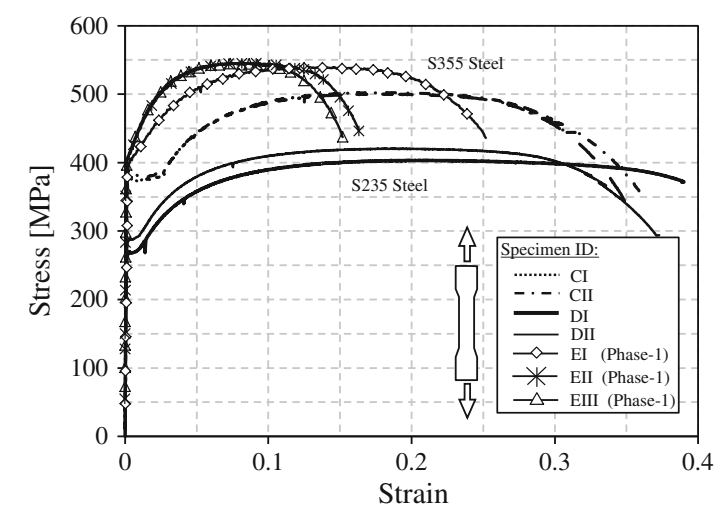

Therefore, results may be non-conservative for situations where significant tank-soil penetration is expected.

\subsection{Material characterization}

Tensile coupon specimens were taken directly from the base-plate material and tested to determine actual material properties. Several material specimens of each nominal steel grade (S355 J2+N and S235 JR+AR) and fabrication batch (Phase-1 and Phase-2) were taken from the base-plates of the tank specimens and tested to failure in tension in accordance to ASTM Standard E-8 (ASTM E-8 2002). All tests were conducted on a $200 \mathrm{kN}$ universal testing machine with strain measurements taken using an optical extensometer. Table 2 provides details for each tensile coupon specimen and Fig. 5 presents the material stress-strain relationships.

The parameter used to measure ductility in this study is the average material fracture strain, $\varepsilon_{f}$. From Fig. 5, the average $6 \mathrm{~mm}$ plate fracture strain values for the S355 Phase-1, S355 Phase-2, and S235 material grades are 0.19, 0.36, and 0.38, respectively, indicating significantly higher ductility for the S235 and S355 Phase-2 steels. Note that these ductility values are all greater than the minimum recommended fracture strain of 0.15 in Eurocode 3 part 1 (EC3-1 1992), and with similar ductility requirements adopted in the Swiss ordinances 
Fig. 6 Comparison between expected and measured membrane stress in specimen $\mathrm{C}-2$ (6 mm, S355, 0.4 rad)

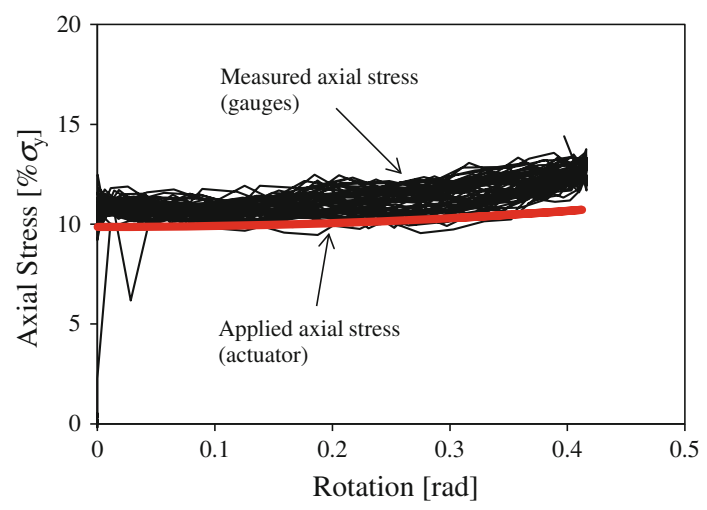

Fig. 7 Comparison between expected and measured base-plate rotation in specimen C-2 (6 mm, S355, 0.4 rad)

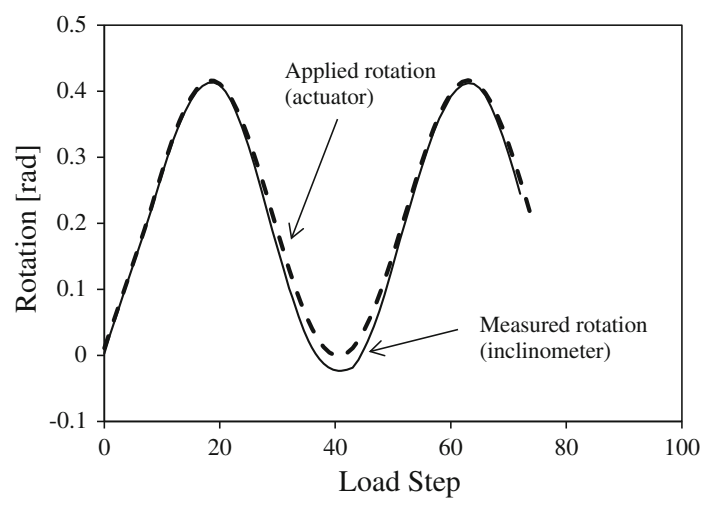

as far back as 1892 (SIA 1892), the mean ductility value of 0.19 for the S355 Phase-1 steel is assumed on the lower end of expected ductility for existing tanks.

\section{Experimental results and discussion}

\subsection{Verification of experimental parameters}

To ensure the quality of fatigue results, the applied rot ation and membrane stress were verified using measurements taken directly from the test specimen. Strain gauge measurements and inclinometer readings were compared with expected demands applied during testing. Fig. 6 compares the expected axial stress (from the vertical load-controlled actuator) and the actual base-plate stress (from gauges on the specimen) for specimen C-2 (6 mm, S355, $0.4 \mathrm{rad}$ ). Fig. 7 compares the expected and actual base-plate rotation for the same C-2 specimen. Expected values are similar to values measured directly from the test specimen, validating the applied membrane stress and rotation during testing. Note in Fig. 7 that the inclinometer reading is slightly lower than the applied rotation due to residual plate curvature following the first inelastic load cycle. 


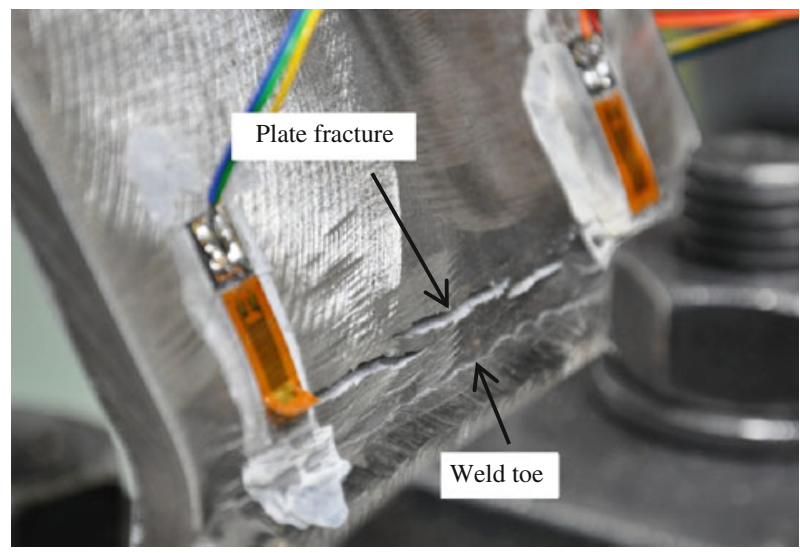

Fig. 8 Fracture in specimen A-1 $(10 \mathrm{~mm}, 0.5 \mathrm{rad}, \mathrm{S} 355$ steel $)$ above the weld toe region

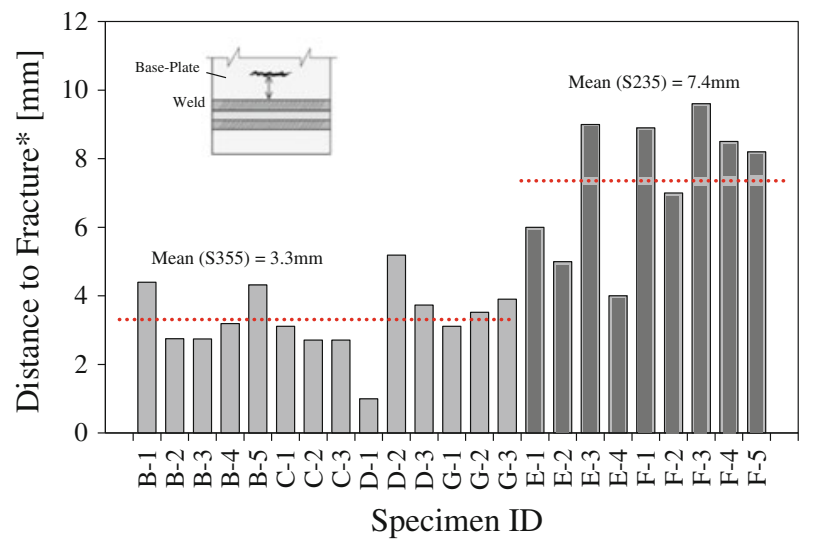

Fig. 9 Distance from weld toe to fracture for each specimen $[*$ distance from weld toe to fracture edge (at plate centerline)]

\subsection{Description of connection behavior}

All specimens failed outside the weld toe region. In each case, initial fractures occurred at the center of the base-plate above the weld region, and propagated outward toward the edge of the baseplate. Initial fractures formed on the inside face of the tank base-plate (the face that would be in contact with liquid) during loading and on the outside face of the base-plate during unloading. Fractures propagated through the plate thickness from each face of the base-plate during repeated loading cycles. Confinement stresses are highest at the base-plate center, and the origination of fractures in the base-plate center somewhat confirm the findings in Prinz and Nussbaumer (2012), which suggests fatigue capacity reductions under multi-axial stress states.

Figure 8 shows a typical fracture originating near the center of the base-plate above the weld toe, and Fig. 9 plots the fracture location for each specimen, measured from the weld toe at the base-plate center. From Fig. 9, the average fracture in the S355 steel specimens initiates $3.3 \mathrm{~mm}$ from the weld toe. Interestingly, fractures in the more ductile S235 steel 


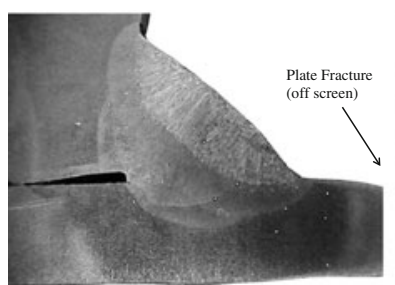

(a)

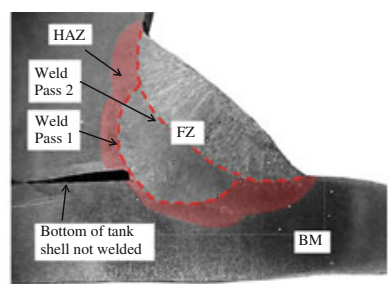

(b)

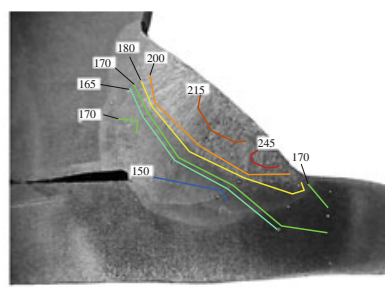

(c)

Fig. 10 Welded connection cross-section prepared using metallographic techniques; a prepared surface, b identified features, and $\mathbf{c}$ Vickers hardness test contours

initiated $4.1 \mathrm{~mm}$ farther away from the weld toe (on average) than those in the less ductile S355 steel (compare 7.4 vs. $3.3 \mathrm{~mm}$ in Fig. 9). One possible explanation is that the overmatching conditions of the weld move the maximum straining and maximum strain range away from the weld and weld HAZ and into the base material.

Metallographic techniques and hardness testing confirm that base-plate fractures occur away from the weld toe and weld HAZ. To distinguish between the weld HAZ, base-material (BM), and weld material (FZ), a sample tested connection was polished with abrasive paper and diamond powder of increasing fineness (mirror polishing down to $1 \mu \mathrm{m}$ ), and then surface etched with a Nital solution $\left(5 \% \mathrm{HNO}_{3}\right.$ per $100 \mathrm{ml}$ of ethanol). Figure 10a shows the prepared specimen surface and Fig. 10b identifies the different weld features (BM, FZ, and HAZ). Vickers hardness testing on the prepared surface identified variations in material parameters within the weld region, and helped determine the location of the HAZ (see Fig. 10c). Hardness testing was performed using a $1 \mathrm{~kg}$-force with an applied duration of $16 \mathrm{~s}$ according to ASTM standard E-384 (ASTM E-384 2011). Base-plate fractures occur outside the weld toe and weld HAZ, indicating that properties of the base material govern fatigue capacity rather than weld material properties or properties from within the weld heat affected zone (HAZ).

\subsection{Connection fatigue life}

The fatigue life of each connection is defined in this study as the number of constant range strain cycles required to obtain complete fracture of the specimen cross-section. Table 3 presents the fatigue-life values for each specimen tested, including the mean fatigue value for each strain range and material group. As expected, lower rotations (lower strain ranges) result in increased fatigue life (compare specimens in Group B with those in Group D). The lowest fatigue value for the $6 \mathrm{~mm} \mathrm{S355} \mathrm{Phase-2} \mathrm{plates} \mathrm{tested} \mathrm{is} 59$ cycles at an applied rotation of 0.5 rad. Additionally, specimens in Groups E and F fabricated with S235 steel had higher fatigue life than corresponding specimens of S355 steel (compare with specimens in Groups $\mathrm{C}$ and D). Note that the number of cycles measured in Table 3 is significantly higher

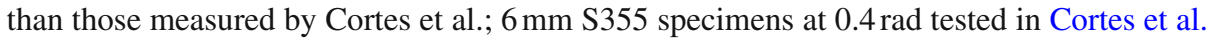
(2011) failed near 23 cycles, compared to 137 cycles in the present S355 Phase-2 tests.

Data sets from the S355 Phase-1 and Phase- 2 material batches cannot be combined into a general S355 material data set unless the means and variances between each data set are statistically negligible. To assess the data equivalence between the Phase- 1 and Phase-2 material batches, a two-tailed Student's $t$ test is applied along with a chosen level of risk, $\alpha_{r}$, equal to $5 \%$ (95\% confidence). This process is outlined in the International Institute of 
Table 3 Experimental fatigue life values

\begin{tabular}{|c|c|c|c|c|c|c|c|c|c|}
\hline Test no & Specimen & $\begin{array}{l}\text { Base } \\
\text { thickness } \\
(\mathrm{mm})\end{array}$ & $\begin{array}{l}\text { Rotation } \\
\text { (rad) }\end{array}$ & $\begin{array}{l}\text { Nominal } \\
\text { axial load } \\
(\mathrm{kN})\end{array}$ & $\begin{array}{l}\text { Steel } \\
\text { grade }\end{array}$ & $N_{f}$ & $\mu$ & $\begin{array}{l}C I_{\text {lower }} \\
(95 \%)\end{array}$ & $\begin{array}{l}C I_{\text {upper }} \\
(95 \%)\end{array}$ \\
\hline 1 & A-1 & 10 & 0.5 & 57 & $\mathrm{~S} 355^{\mathrm{a}}$ & 32 & & & \\
\hline 2 & A-2 & 10 & 0.5 & 57 & $\mathrm{~S} 355^{\mathrm{a}}$ & 32 & 31.3 & 28.2 & 34.3 \\
\hline 3 & A-3 & 10 & 0.5 & 57 & $\mathrm{~S} 355^{\mathrm{a}}$ & 33 & & & \\
\hline 4 & A-4 & 8 & 0.5 & 45 & $\mathrm{~S} 355^{\mathrm{a}}$ & 29 & & & \\
\hline 5 & B-1 & 6 & 0.5 & 34 & S355 & 59 & & & \\
\hline 6 & B-2 & 6 & 0.5 & 34 & S355 & 67 & & & \\
\hline 7 & B-3 & 6 & 0.5 & 34 & S355 & 73 & 64.5 & 57.3 & 71.7 \\
\hline 8 & B-4 & 6 & 0.5 & 34 & S355 & 60 & & & \\
\hline 9 & B-5 & 6 & 0.5 & 34 & S355 & 62 & & & \\
\hline 10 & C-1 & 6 & 0.4 & 34 & S355 & 132 & & & \\
\hline 11 & C-2 & 6 & 0.4 & 34 & S355 & 125 & 137.3 & 100.1 & 174.5 \\
\hline 12 & C-3 & 6 & 0.4 & 34 & S355 & 154 & & & \\
\hline 13 & D-1 & 6 & 0.3 & 34 & S355 & 306 & & & \\
\hline 14 & D-2 & 6 & 0.3 & 34 & S355 & 310 & 293.6 & 230.2 & 357.0 \\
\hline 15 & D-3 & 6 & 0.3 & 34 & S355 & 264 & & & \\
\hline 16 & E-1 & 6 & 0.3 & 23 & $\mathrm{~S} 235$ & 476 & & & \\
\hline 17 & E-2 & 6 & 0.3 & 23 & $\mathrm{~S} 235$ & 369 & 404.3 & 312.6 & 496.0 \\
\hline 18 & E-3 & 6 & 0.3 & 23 & $\mathrm{~S} 235$ & 348 & & & \\
\hline 19 & E-4 & 6 & 0.3 & 23 & $\mathrm{~S} 235$ & 424 & & & \\
\hline 20 & F-1 & 6 & 0.4 & 23 & $\mathrm{~S} 235$ & 177 & & & \\
\hline 21 & $\mathrm{~F}-2$ & 6 & 0.4 & 23 & S235 & 183 & & & \\
\hline 22 & F-3 & 6 & 0.4 & 23 & $\mathrm{~S} 235$ & 179 & 160.9 & 127.1 & 194.7 \\
\hline 23 & F-4 & 6 & 0.4 & 23 & $\mathrm{~S} 235$ & 146 & & & \\
\hline 24 & F-5 & 6 & 0.4 & 52 & $\mathrm{~S} 235$ & 120 & & & \\
\hline 25 & G-1 & 5 & 0.5 & 28 & S355 & 86 & & & \\
\hline 26 & G-2 & 5 & 0.5 & 28 & S355 & 87 & 87.8 & 81.8 & 93.8 \\
\hline 27 & G-3 & 5 & 0.5 & 28 & S355 & 91 & & & \\
\hline
\end{tabular}

a S355 material from batch in Phase-1

Welding's (IIW's) Guidance for the Application of the Best Practice Guide on Statistical Analysis of Fatigue Data (Huther et al. 2008). Table 4 demonstrates the statistical equivalence test between the S355 Phase-1 and Phase-2 batch specimens (refer to Table 3 and Cortes et al. (2011) for Phase- 2 and Phase-1 material batch fatigue values, respectively). From Table 4, as expected, the variations in fatigue life are significant and results should be kept as two independent data-sets.

\subsection{Influence of material ductility on fatigue life}

The significant difference between the fatigue results in this study and those obtained in Cortes et al. is due to material ductility, as material testing indicates a significant increase in ductility with the S355 Phase-2 batch over the S355 Phase-1 batch used by Cortes et al. 
Table 4 T test of data equivalence hypothesis for $6 \mathrm{~mm}, \mathrm{~S} 355$ plates at $0.3 \mathrm{rad}$

\begin{tabular}{lll}
\hline & $\begin{array}{l}\text { Cortes et al. data } \\
(6 \mathrm{~mm}, \mathrm{~S} 355,0.3 \mathrm{rad})\end{array}$ & $\begin{array}{l}\text { Phase-2 data } \\
(6 \mathrm{~mm}, \mathrm{~S} 355,0.3 \mathrm{rad})\end{array}$ \\
\hline Sample size $[\mathrm{n}]$ & 2 & 3 \\
Mean value $\left[\mathrm{X}_{\mathrm{m}, \mathrm{i}}=\Sigma \mathrm{X}_{\mathrm{i}} / \mathrm{n}\right]$ & 92.9 & 293.6 \\
$\Sigma\left(\mathrm{X}_{\mathrm{i}}-\mathrm{X}_{\mathrm{m}}\right)^{2}$ & 25.9 & $1,302.8$ \\
Estimated variances $\left[\mathrm{v}_{\mathrm{i}}=\Sigma\left(\mathrm{X}_{\mathrm{i}}-\mathrm{X}_{\mathrm{m}}\right)^{2} / \mathrm{n}-1\right]$ & 25.9 & 651.4 \\
Common variances $\left[\mathrm{v}=\left(\left(\mathrm{n}_{1}-1\right) \mathrm{v}_{1}\right.\right.$ & 442.9 & \\
$\left.\left.\quad+\left(\mathrm{n}_{2}-1\right) \mathrm{v}_{2}\right) /\left(\mathrm{n}_{1}+\mathrm{n}_{2}-2\right)\right]$ & & \\
Difference variance $\left[\mathrm{v}_{\mathrm{d}}=\mathrm{v}\left(1 / \mathrm{n}_{1}+1 / \mathrm{n}_{2}\right)\right]$ & 369.1 & \\
Critical value $\left[\mathrm{t}\left(\alpha_{r}, n_{i}\right)\right]$ & 3.182 & \\
Criteria $\left[\mathrm{Cr}=\left|\mathrm{X}_{\mathrm{m} 1}-\mathrm{X}_{\mathrm{m} 2}\right|-\mathrm{t}\left(\mathrm{v}_{\mathrm{d}}\right)^{1 / 2}\right]$ & $139.6>0$ therefore the hypothesis of equivalence \\
& has to be rejected
\end{tabular}

Fig. 11 Comparison between plate ductility and fatigue life

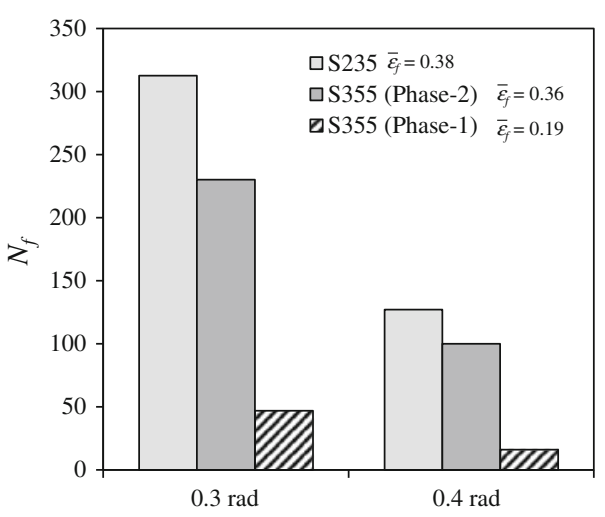

Increasing ductility drastically increases the fatigue life of tank connections. Figure 11 shows the fatigue life (in cycles) for tank specimens of each ductility value, loaded at two different levels of rotation $(0.3$ and $0.4 \mathrm{rad})$, and considering the lower bound $95 \%$ confidence interval. From Fig. 11, specimens fabricated from the more ductile S235 steel $\left(\varepsilon_{f}=0.38\right)$, showed an average $525 \%$ increase in fatigue life over specimens fabricated from S355 Phase1 steel $\left(\varepsilon_{f}=0.19\right)$ and an average $28 \%$ increase in fatigue life over the S355 Phase-2 steel specimens $\left(\varepsilon_{f}=0.36\right)$ (at $0.3 \mathrm{rad}$ rotation). Tank specimens tested at $0.4 \mathrm{rad}$ showed similar fatigue response when material ductility was increased (see Fig. 11).

For tank design or assessment purposes it is useful to relate connection rotation and $N_{f}$. To do this, a Coffin-Manson (Coffin Jr 1954; Manson 1954) power law relationship between rotation and $N_{f}$ (see Eq. 1) has been adopted to create fatigue-life (capacity) curves from the test data.

$$
N_{f}=\left(\frac{1}{c \cdot \theta^{c}}\right)
$$

In Eq. $1, N_{f}, \theta, c$, and $C$ are the number of cycles to failure, rotation range, and slope and intercept of the fatigue-life curve, respectively. Figure 12 shows the fatigue-life curves for tank specimens of each ductility value. Presented in Fig. 12 are the individual test fatigue capacities, along with the mean and lower bound $95 \%$ confidence lines for assessing connection 
Table 5 Coffin-Manson coefficients for mean and lower-bound confidence interval fatigue-life curves

$\begin{array}{lllr} & \mu & 4.22 & 1.96 \\ & 95 \% \mathrm{CI} & 4.23 & 3.18 \\ & \mathrm{~S} 355 \text { Phase-2 }{ }^{\mathrm{b}} & & 0.127 \\ & \mu & 3.04 & 0.119 \\ & 95 \% \mathrm{CI} & 2.73 & 0.112 \\ & \mathrm{~S} 235 & & 3.17 \\ \text { a S355 Phase-1 test batch } & \mu & 3.13 & 0.138 \\ \text { b S355 Phase-2 test batch } & 95 \% \mathrm{CI} & \end{array}$

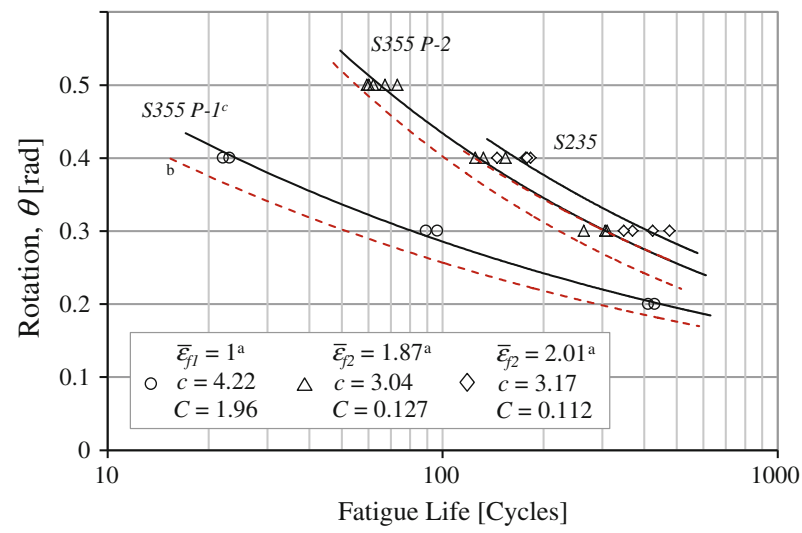

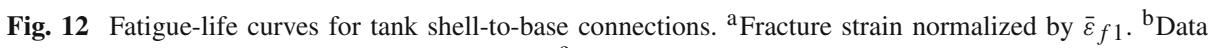
uncertainty shown with $95 \%$ confidence interval. ${ }^{\mathrm{c}} \mathrm{S} 355$ Phase- 1 test batch

capacity. Capacity increase with increased ductility is evident by shifting of the curves to the right (higher fatigue life). Table 5 provides the Coffin-Manson coefficients for the mean and lower-bound $95 \%$ confidence interval fatigue-life curves presented in Fig. 12.

Using the Coffin-Manson coefficients in Table 5 along with the corresponding curve ductility values, equations for $c$ and $C$ are determined in terms of base-plate material ductility as $C=1.197 \cdot \varepsilon_{f}^{-0.46}$ and $C=0.018 \cdot \varepsilon_{f}^{-42}$. Note that these equations for $c$ and $C$ assume a power-law relationship with $\varepsilon_{f}$, and are based only on the experimental performance of $6 \mathrm{~mm}$ plates. Substituting $c$ and $C$ into Eq. 1 allows for the estimation of connection fatigue-life directly in terms of base-plate ductility, $\varepsilon_{f}$, and applied rotation range, $\theta$ (see Eq. 2). To extend Equation 2 to account for thicker plates, a knock-down factor of $(1.6-t / 10) * N_{f}$ is proposed based on the limited testing of 10 and $8 \mathrm{~mm}$ plates in Cortes et al. Fig. 13 compares the estimated fatigue-life curves for $6 \mathrm{~mm}$ plates of various ductility values with experimental results.

$$
N_{f}=\frac{555}{\varepsilon_{f}^{(-42)} \theta^{\left(1.97 \varepsilon_{f}^{-0.46}\right)}}
$$




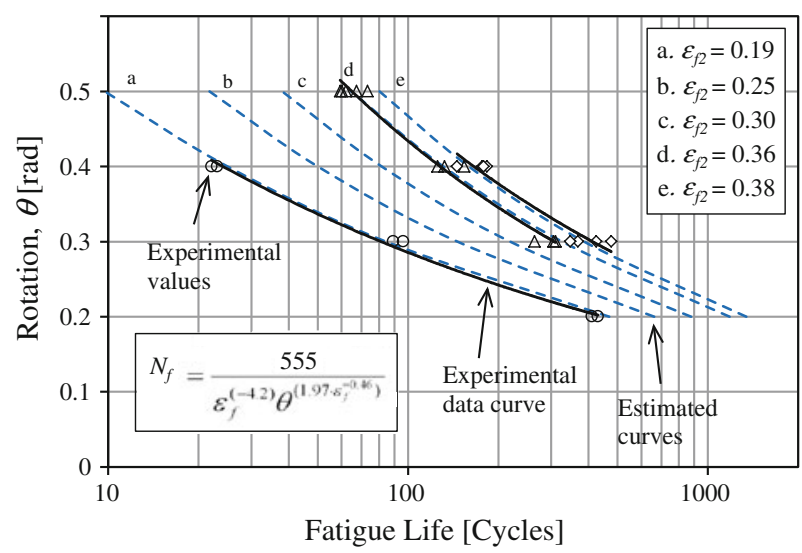

Fig. 13 Estimated fatigue-life curves along with experimental result

Fig. 14 Influence of plate thickness on plate surface strains

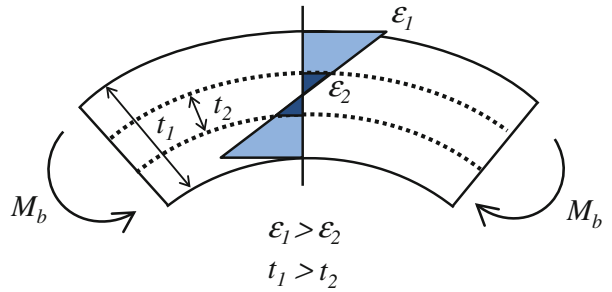

\subsection{Effect of plate thickness on connection fatigue}

Tank connection fatigue has two stages: fracture initiation at the plate surface, and propagation of this fracture through the plate thickness. For the case of low-cycle fatigue with no initial flaws or imperfections, the fracture initiation stage is onset by large inelastic strains which occur at the plate tensile surface during bending. Following initiation, propagation of the crack is dependent on the ability of the material to dissipate the large strain concentrations at the fracture tip.

Because of this two-stage process, the effects of base-plate thickness are difficult to determine, without first determining material ductility. In general, for the same applied rotation, inelastic strains at the surface of thick plates are greater than those in thin plates (see Fig. 14), indicating earlier onset of fracture initiation in the thicker plates; however, in previous testing by Cortes et al., thin base-plates failed earlier than thicker ones ( 84 cycles for $6 \mathrm{~mm}$ specimen PL6NT10-1 vs. 126 cycles for $10 \mathrm{~mm}$ specimen PL10NT10-1). Current testing indicates the opposite; with thicker specimens failing at fewer cycles than thinner ones (compare $N_{f}$ values for 5, 6, and $10 \mathrm{~mm}$ specimens in Table 3 ).

The increased fatigue life of thick plates in previous testing by Cortes et al. (2011) is due to plate ductility. Material testing of the Phase-1 S355 batch indicates higher ductility with increased plate thickness (mean fracture strains equaled $0.28,0.25$, and 0.19 for the 10,8 , and $6 \mathrm{~mm}$ plates, respectively). This decrease in ductility with decrease in plate thickness may be due to cold-working in the last step of the production process. During cold-working, plates are rolled (squeezed) at room temperature through small openings, decreasing plate thickness to final value and inducing plastic strains in the material. Note that the $6 \mathrm{~mm}$ specimens from 


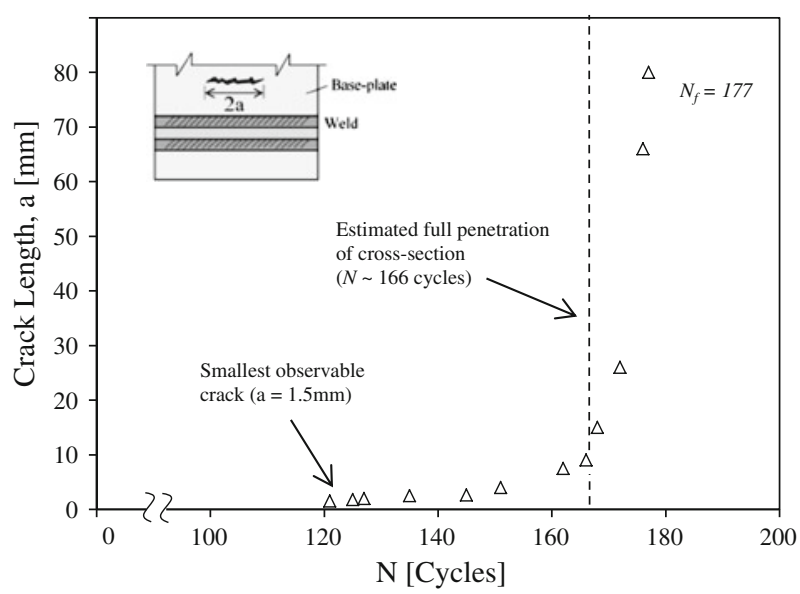

Fig. 15 Crack length versus number of cycles (Specimen F-1, 6 mm, S235, 0.4 rad)

the S355 Phase-2 batch had higher ductility values compared to the $10 \mathrm{~mm}$ specimens from the S355 Phase-1 batch.

\subsection{Initial spillage condition and base-plate crack progression}

It is understood that tank connection service life extends beyond the fracture initiation stage, but it is unclear at what point the service life should end or what constitutes failure. In this study, the tank connections "fail" only after complete rupture of the $160 \mathrm{~mm}$ wide base-plate is achieved; however, prior to complete rupture there exists the possibility for tank contents to leak, due to cracks penetrating the plate thickness. Additionally, due to the definition of fatigue life used in this study, the chosen specimen width will affect connection capacity. It is therefore interesting to investigate the number of cycles required to achieve full crack penetration of the base-plate (number of cycles to initiate leakage).

To measure crack growth during testing, controlled digital images were taken of the specimen base-plate every cycle and crack length was measured using a scale attached near the fracture initiation region. A fluorescent lamp was placed opposite from the camera to capture any light penetrating the fractured plate.

First complete crack penetration was observed at $93 \%$ of the total connection fatigue life, indicating that the majority of crack growth occurs towards the end of the plate fatigue life. In specimen F-1, fabricated from S235 steel and having a $6 \mathrm{~mm}$ base-plate thickness, fatigue crack length grew exponentially, with the first complete crack penetration observed after 166 cycles at 0.4 rad (complete plate rupture after 177 cycles) (see Fig. 15). Exponential growth is typical for fatigue driven behavior.

\section{Summary and conclusions}

In this study, 27 tank shell-to-base connections were subjected to constant range static uplift cycles and constant membrane stress (biaxial loading). The 27 specimens represented two steel material grades (S235 and S355) and three levels of uplift rotation (0.3, 0.4, and $0.5 \mathrm{rad})$. Transverse butt-welds (welds perpendicular to the shell-to-base welds) often present in tank 
base-plates due to fabrication techniques were not considered in the connection test specimens. Cyclic displacements and membrane loading were applied until complete rupture of the tank base-plate. The following conclusions are based on the static cyclic testing of 27 welded shell-to-base connections:

1. Fractures originate near the center of the base-plate where confinement stresses are highest, and propagate outward towards the plate edge. This indicates potential capacity reduction for base-plates under multi-axial loading (combined radial tension and circumferential compression). The effects of these multi-axial strain states on the capacity of shell-to-base connection should be investigated experimentally.

2. Increasing material ductility increases connection fatigue life. All specimens failed in the base material away from the weld toe and weld HAZ; indicating that, in overmatching weld situations such as those relevant and tested herein, the base material strain capacity has a strong influence on fatigue. By increasing strain capacity of the base material, fracture initiation and complete propagation are offset resulting in increased fatigue life. However, given the heavy influence of base-plate ductility away from the shell-to-base weld, the influence of additional transverse butt-welds created during tank fabrication may significantly affect base-plate ductility and should be investigated in future research.

3. Due to higher surface strains, thicker plates fail earlier than thinner plates when material ductility is the same; however, for plates between 5 and $10 \mathrm{~mm}$ thick (the thicknesses tested in the Phase-1 and Phase-2 studies) this plate thickness effect can be overcome with higher material ductility. The Phase- $16 \mathrm{~mm}$ plate fatigue life curves presented in Cortes et al. therefore still represent the most conservative connection rotation capacity, as long as higher ductility is ensured for thicker plates.

4. The majority of crack growth occurs towards the end of the plate fatigue life, indicating that complete rupture of the $160 \mathrm{~mm}$ wide specimens is representative of connection capacity. Complete crack penetration of the base-plate was observed at $93 \%$ of the total connection fatigue life.

5. All connections tested sustained multiple cycles at rotations higher than the current EC84 limit. The fatigue life curve representing the lower bound $95 \%$ confidence interval (see Fig. 12) suggests that connections of S355 steel having a material fracture strain, $\varepsilon_{f}$, near 35 and $10 \% \sigma_{y}$ applied axial stress could withstand 55 cycles with a range of $0.5 \mathrm{rad}$ prior to failure. This rotation is much higher than the allowed $0.2 \mathrm{rad}$ for an unknown number of cycles presented in EC8-4.

Acknowledgments This research was financially supported by CARBURA and the Swiss Federal Office for the Environment (OFEV). Gustavo Cortes, Martin Koller, and Thomas Wenk provided valuable input during the early stages of the project. The authors accept full responsibility for the conclusions presented.

\section{References}

ASTM E-8 (2002) Standard test methods for tension testing of metallic materials. E8, West Conshohicken ASTM E-384 (2011) Standard test method for Knoop and Vickers hardness of materials. E384, in annual book of ASTM, vol 03.01, West Conshohicken

Coffin LFJr (1954) A study of the effects of cyclic thermal stresses in ductile metals. ASME 76:931-950

Cortes G, Nussbaumer A, Berger C, Lattion E (2011) Experimental determination of the rotational capacity of wall-to-base connections in storage tanks. J Constr Steel Res 67:1174-1184

Eurocode-3 (1992) Part 1-1: general rules and rules for buildings. ENV 1993-1-1, European Committee for Standardization, Brussels

Eurocode-8 (1998) Part 4: silos, tanks, and pipelines. ENV 1998-4, European Committee for Standardization, Brussels 
Fujikazu S, Akira I, Hajime H, Yukio M (1988) Experimental study on uplifting behavior of flat-based liquid storage tanks without anchors. In: Proceedings of the 9th world conference on earthquake engineering. Tokyo-Kyoto, pp 649-654

Haroun MA (1983) Behaviour of unanchored oil storage tanks: imperial valley earthquake. J Tech Topics Civ Eng 109(1):23-38

Housner GW (1963) The dynamic behavior of water tanks. Bull Seismol Soc Am 53(2):381-387

Huther M, Galtier A, Marquis G (2008) Guidance for the application of the best practice guide on statistical analysis of fatigue data. International Institute of Welding (IIW). Commission XIII-WG1-132-108

Jacobsen LS (1949) Impulsive hydrodynamics of fluid inside a cylindrical tank and of fluid surrounding a cylindrical pier. Bull Seismol Soc Am 39(3):189-203

Koller M (2003) Erdbebensicherheit bestehender unverankerter stehtanks in bezug auf storfallrelevante schaden. Report No. TB 245-02/MK. Resonance Ingenieurs-Conseils

Leon GS, Kausel EAM (1986) Seismic analysis of fluid storage tanks. J Struct Eng 112(1):1-18

Malhotra PK (1995) Base uplifting analysis of flexibly supported liquid-storage tanks. Earthq Eng Struct Dyn 24:1591-1607

Malhotra PK, Veletsos AS (1994a) Beam model for base-uplifting analysis of cylindrical tanks. J Struct Eng 120(12):3471-3488

Malhotra PK, Veletsos AS (1994b) Uplifting analysis of base plates in cylindrical tanks. J Struct Eng 120(12):3489-3505

Manos GC, Clough RW (1985) Tank damage during the May 1983 Coalinga earthquake. Earthq Eng Struct Dyn 13:449-466

Manson SS (1954) Behavior of materials under conditions of thermal stress. National Advisory Committee for Aeronautics. Technical note 2933. Tennessee (USA)

NZSEE (2009) Seismic design of storage tanks. New Zealand National Society for Earthquake Engineering, Wellington

Peek R (1988) Analysis of unanchored liquid storage tanks under lateral loads. Earthq Eng Struct Dyn 16:10871100

Peek R, Jennings PC (1988) Simplified analysis of unanchored tanks. Earthq Eng Struct Dyn 16:1073-1085

Prinz GS, Nussbaumer A (2012) Fatigue analysis of liquid storage tank shell-to-base connections under multiaxial loading. Eng Struct 40:75-82

SIA (1892) Fur die Berechnung, die Ausfuhrung und den Unterhait der Bauten aus Stahl, Beton, Eisenbeton und Holz-Teil 2. Normen des Schweizerischer Ingenieur und Architektenverein, Switzerland 